\title{
FEM analysis of steel-concrete composite bridges with encased perforated steel strips
}

\author{
Patrícia Vaňová ${ }^{1, *}$, Vincent Kvočák ${ }^{1}$, Viktória Kožlejová ${ }^{1}$, Daniel Dubecký ${ }^{1}$ and Ruslan \\ Kanishchev $^{1}$ \\ ${ }^{1}$ TUKE, Faculty of Civil Engineering, Vysokoškolská 4, 04200 Košice, Slovakia
}

\begin{abstract}
One of the newest contributions to the science of bridges are steel-concrete composite bridges with encased perforated steel strips. Their main advantages are their low height, low usage of materials and therefore lower cost of the bridge. They are mainly used as short span railway bridges (under $20 \mathrm{~m}$ of length). Main focus of today researchers and structural engineers in this area is to improve the geometry of the steel strip - and therefore find new types with lower usage of material and higher shear strength. At Technical University of Košice, Faculty of Civil Engineering, several new types have been developed and tested. In order to properly measure the shear strength, the push-out tests had to be carried. They track the dependence between load (typed by loading conditions) and slip. These experiments were performed at Laboratory of Excellent Research in Košice. In this article is closely described software modelling of a strip developed at Faculty of Civil Engineering, the experiments performed as well as the results found.
\end{abstract}

\section{Introduction}

Numerical study of performed experiments is important in order to fully watch and understand inside stresses and behaviour of the specimen during the testing as well as for the parametric study.

Several papers were published about this topic in the past. Oguejiofor and Hosain have described one of the first finite element analysis of push-out tests of specimens resisting shear which contained steel perfobond strip, as early as 1995 . They created the numerical model in ANSYS [1]. Bouchair et al. did the analysis of push-out tests of specimens with shear studs in ATENA software [2]. Nguyen and Kim analysed the experiments using ABAQUS software [3].

In this article the FE modelling approach of the push-out tests performed onto the specimens with continuous shear connectors using ABAQUS/CAE software is closely described.

\footnotetext{
* Corresponding author: patricia.vanova@tuke.sk
} 


\section{Geometry}

The specimens tested were made out of I-beam IPE 220 cutted longitudinally. The steel strips contained holes of $20 \mathrm{~mm}$ in diameter within $100 \mathrm{~mm}$ from each other, placed in the middle of the strip by height. $12 \mathrm{~mm}$ reinforcement bars, marked 10505 (R), were placed through each hole.

\section{Push-out test}

Standard push-out tests were performed onto three specimens. The load was measured by hydraulic press software and the slip by two inductive displacement sensors placed at the bottom of the middle steel metal.

a)

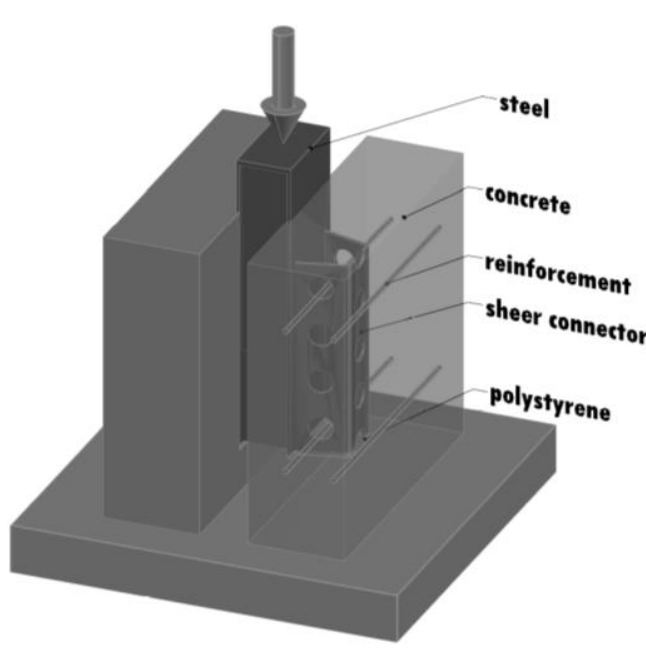

b)

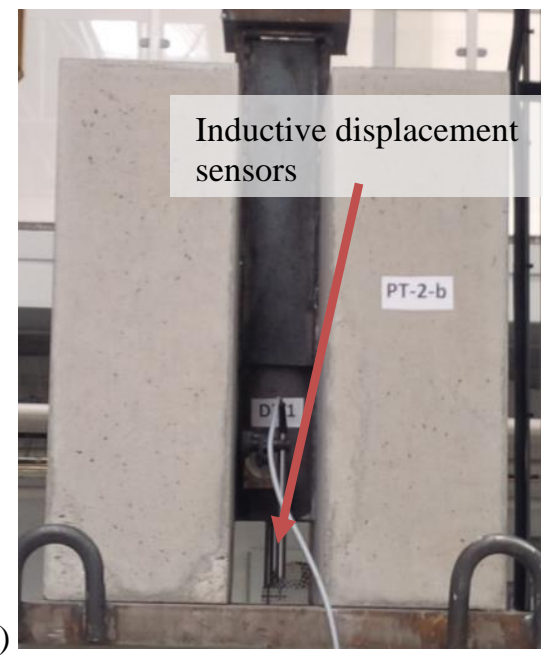

Fig. 1. Push out-tests a) Arrangement of the specimen, b) The real specimen in hydraulic press.

\section{FEM model}

The entire experiment was simulated in ABAQUS/CAE software [4]. The goal was to find a model of which results had lower deviation than $60 \%$, suitable for usage in the further parametric study.

\subsection{Material properties}

\subsubsection{Steel}

Steel used for continuous shear connectors was tested by Faculty of Metallurgy at Technical University of Košice. Tensile tests were performed onto three samples. Yield point was set at the $315.3 \mathrm{MPa}$ (Fig. 2). For Young's Modulus and Mass density the normative values were used. 


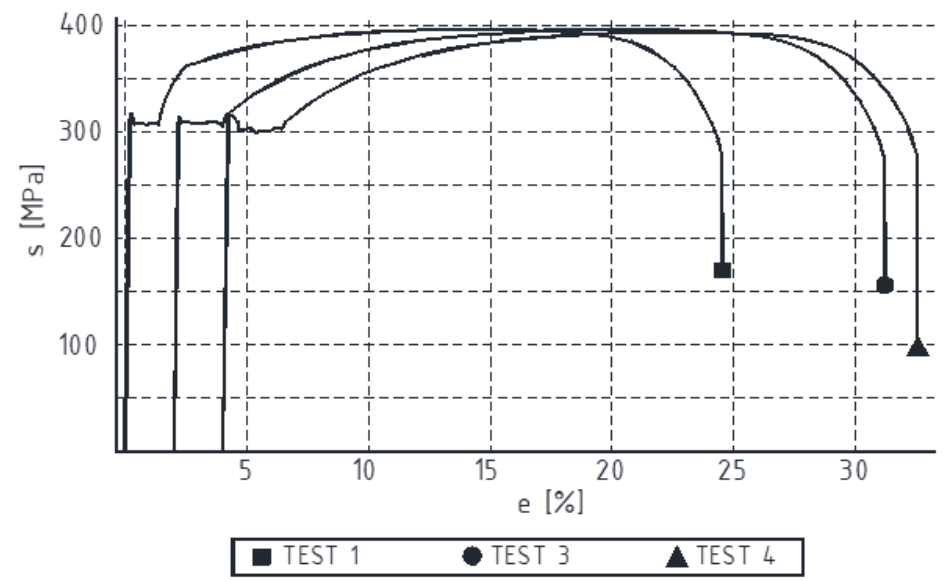

Fig. 2. Tensile tests of steel used for continuous sheer connectors.

\subsubsection{Concrete}

For two concrete blocks, the concrete marked C30/37 of European quality was used. Compressive tests and four-point flexural tests were provided by Laboratory of Excellent Research. The characteristics used for the FEM model are shown in Table 1.

Table 1. Material characteristics of concrete used in software model.

\begin{tabular}{|c|c|c|c|c|}
\hline DENSITY & & Mass density & $2.54 \mathrm{E}-09$ & tonne/mm3 \\
\hline \multirow{2}{*}{ ELASTIC } & & Young's Modulus & 33423.80 & $\mathrm{MPa}$ \\
\hline & & Poisson's ratio & 0.2 & - \\
\hline \multirow{9}{*}{ 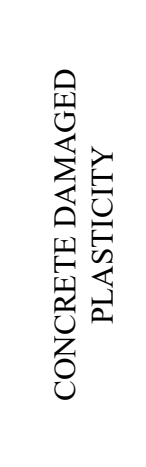 } & \multirow{5}{*}{ Plasticity } & Dilatation Angle & 30 & $\circ$ \\
\hline & & Eccentricity & 0.1 & $\mathrm{~mm}$ \\
\hline & & $\mathrm{fb} 0 / \mathrm{fc} 0$ & 1.16 & - \\
\hline & & K & 0.667 & - \\
\hline & & Viscosity Parameter & 0 & - \\
\hline & \multirow{2}{*}{$\begin{array}{c}\text { Tensile } \\
\text { behaviour }\end{array}$} & Yield Stress & 3.7 & $\mathrm{MPa}$ \\
\hline & & Cracking Strain & 0 & - \\
\hline & \multirow{2}{*}{$\begin{array}{c}\text { Compressive } \\
\text { behaviour }\end{array}$} & Yield Stress & 39.72 & $\mathrm{MPa}$ \\
\hline & & Cracking Strain & 0 & - \\
\hline
\end{tabular}

\subsection{Interaction}

Option 'general contact' was chosen to perform the interaction between steel and concrete parts. 'Hard contact' was set as a global property assignment. One individual property assignment was present between the surface of the strip and the surface of concrete, which comes into contact - tangential behaviour was added, with friction coefficient equal 0.12 . 


\subsection{Load}

In the load module, firstly, the boundaries were fixed - as pinned at the bottom of both concrete blocks. Secondly, loading was done in 114 loading conditions, from which 50LCs created the cycle by dropping and increasing between $100 \mathrm{kN}$ and $350 \mathrm{kN}$, while the specimen still acted elastically. Maximum load, after which the specimen broke, was $1200 \mathrm{kN}$.

\subsection{Mesh}

The defined element for both steel and concrete parts was 4-node linear tetrahedron C3D4. 8-node reduced integration C3D8R element was selected for reinforcement.

a)

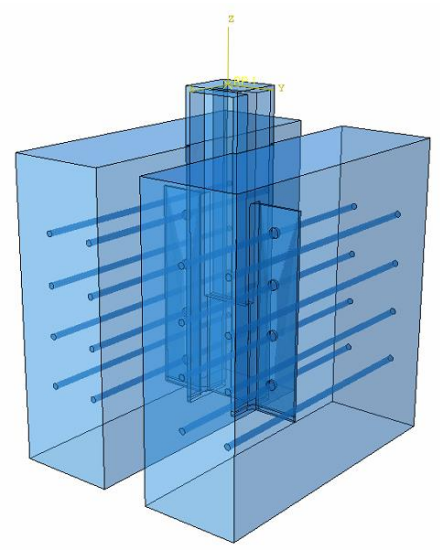

b)

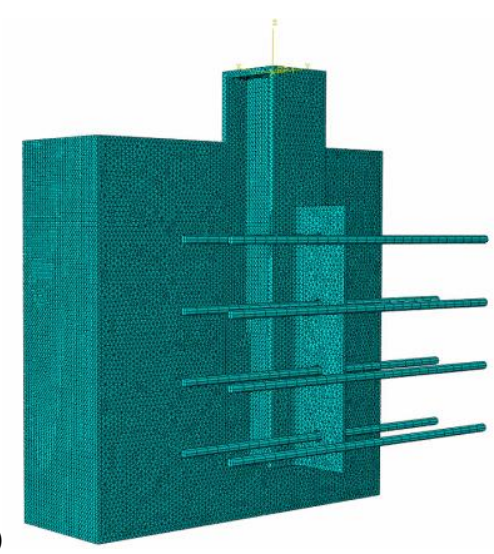

Fig. 3. ABAQUS model a) General model, b) Meshed model.

\section{Results}

The shear resistance of the specimen was determined at $750 \mathrm{kN}$ - at the end of the first, linear (elastic), section of the diagram (Fig. 4), during which the specimens were in good condition, no cracks could be seen. During the second section the slip started to grow and visible cracks were developed. After reaching $1050 \mathrm{kN}$ the slip started to rapidly rise - until the polystyrene between steel and concrete was compressed, the steel strip started to push into the concrete and the specimen was breached. This - third - section was accompanied by visible crack propagation as well as the loud cracking sound effects.

FEM model showed similar results (Fig. 5). The shear resistance was obtained at the same LC $-750 \mathrm{kN}$, but presented with $0.5 \mathrm{~mm}$ higher slip, which manifested the safe side of the FEM model. The most stressed place of the steel strip occurred at the interaction point between the border of hole and the reinforcement bar. 


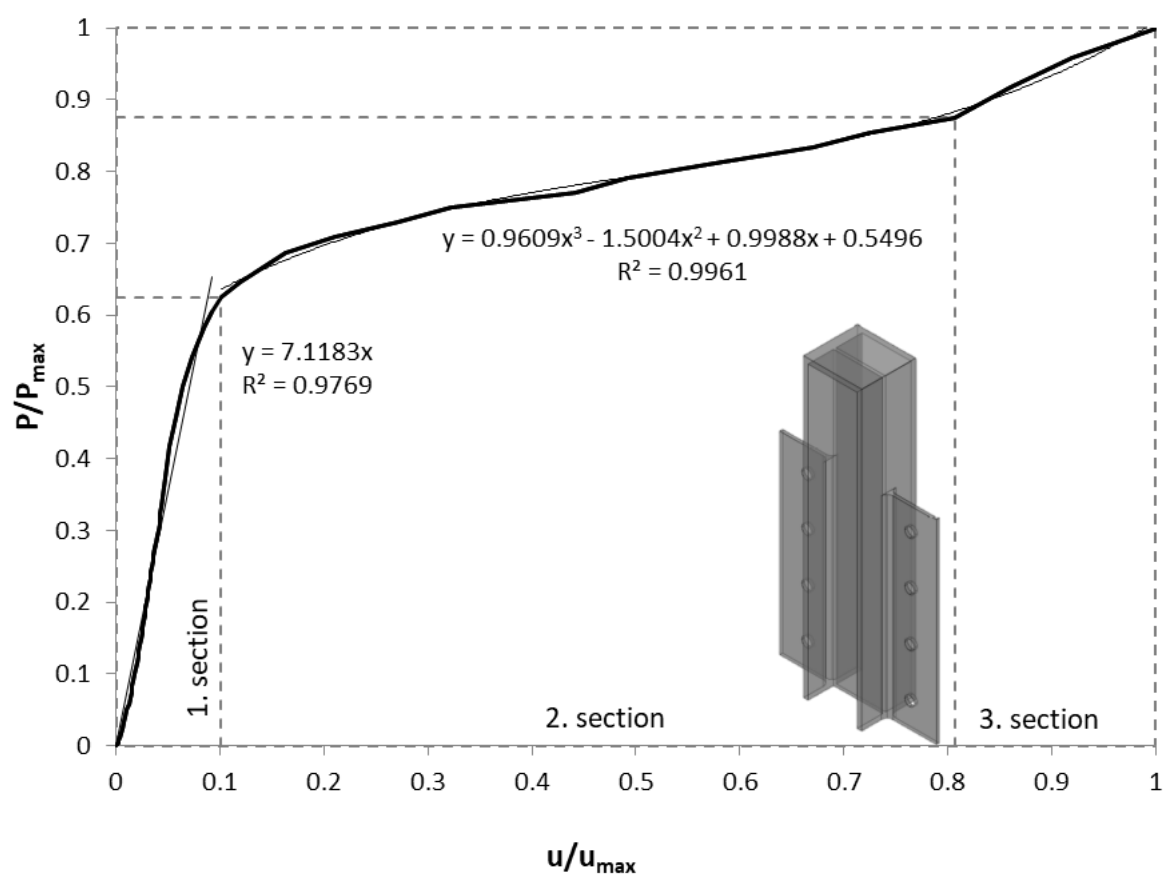

Fig. 4. Diagram showing results of push-out tests.

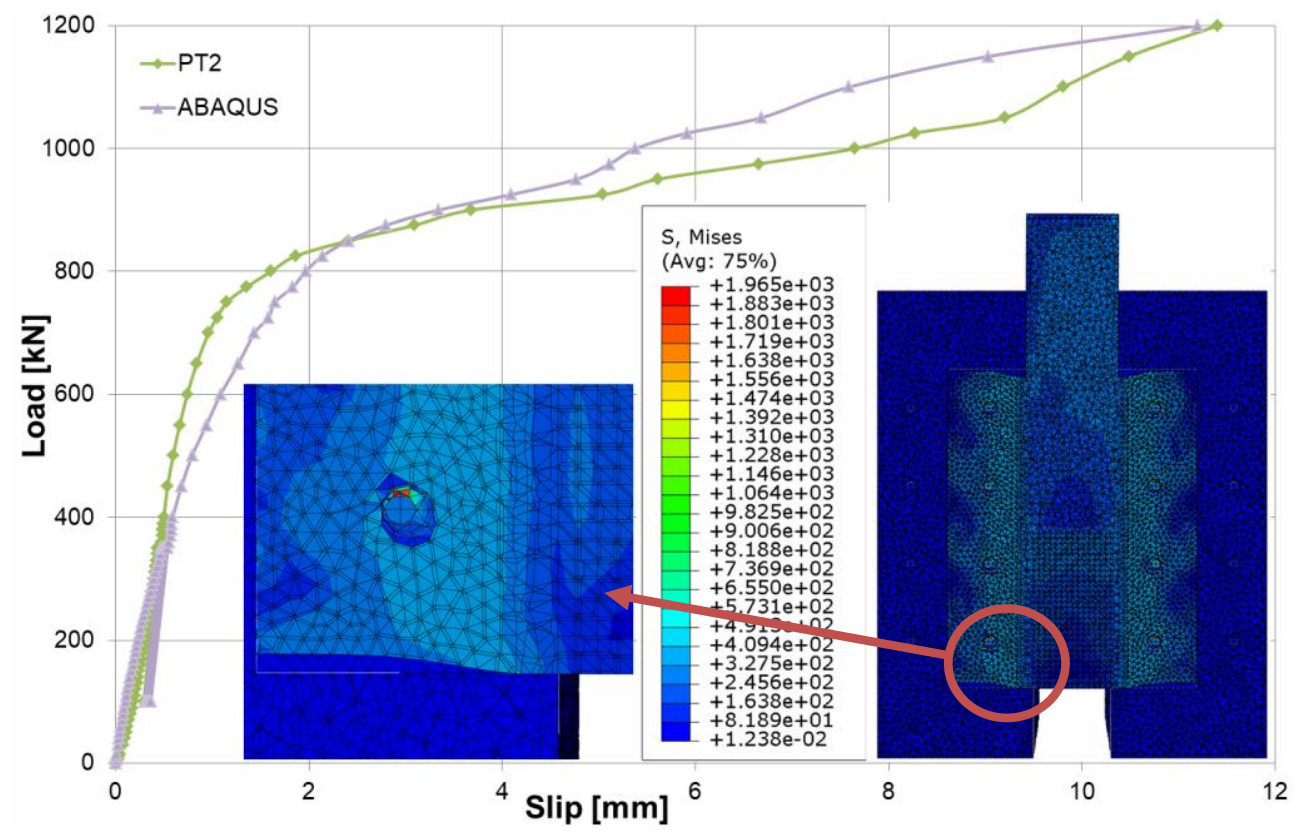

Fig. 5. Comparison between experiment results and the FEM software results. 


\section{Conclusion}

The finite element model was created in ABAQUS software to simulate the real experiment of push-out tests. The deviation between slip of the experiment and FEM model was lower than $60 \%$ during whole process, except for the LCs \#2-7 $(5-50 \mathrm{kN})$. This could be explained by minor shortcomings between the concrete blocks and steel pad of hydraulic press, which could not be put into the software model. In conclusion, the FEM model proved to be sufficiently accurate for use in further parametric study.

The paper has been supported by The projects: VEGA 1/0172/20 "Stress and deformation analysis of load bearing components made out of steel, glass and composite materials", VEGA 1/0374/19 "Multiscale modeling of multi-physical problems of composite structural elements" of the Scientific Grant Agency of the Ministry of Education, science, research and sport of the Slovak Republic and the Slovak Academy of Sciences and by the project Slovak Research and Development Agency under the contract No. APVV-15-0486 "Analysis of Shear Connection Influence in Bridges with Encased Beams".

\section{References}

1. E. C. Oguejiofor, M. U. Hosain, Computers \& Structures 62, 4 (1995)

2. A. Bouchair, J. Bujnak, P. Duratna, A. Lachal, Steel Structures and Bridges 40, 102 107 (2012)

3. H. T. Nguyen, S. E. Kim, J. of Constr. Steel Research 65, 1909 - 1920 (2009)

4. ABAQUS/CAE: User's Manual. Available on the internet: $<$ https://classes.engineering.wustl.edu/2009/spring/mase5513/abaqus/docs/v6.6/books/ usi/default.htm?startat=pt03ch15s12hlb03.html> 